\title{
Applying evaluation criteria for Web-based information sources to paper-based information sources
}

\section{A review of The Meaning of Relativity (Princeton University Press, 1945) by Albert Einstein}

It is hard to imagine a more straightforward or convenient introduction to such a timely topic on Applying evaluation criteria for Web-based information sources to paper-based information sources. For those feeling overwhelmed by cosmological problems in the context of space/ time continua, this tool will be a welcome addition to their repertoire of one-stop, no-nonsense, all-in-one leaming aids and devices.

I rank this resource's accessibility quite high; I was able to get into it quickly and repeatedly throughout the day, even during peak hours. Reliability was also above average because the infrastructure that coordinates its 135 pages functions smoothly. The information retrieval mechanism never locked up or froze, virtually eliminating downtime.

This source is extremely well organized, featuring an outline of the contents in tabular form and consecutive page numbers. I was also pleased not to find the Roman/Arabic numbering glitch, a systems incompatibility problem common in the opening pages of many cellulose-based data products.

The visual layout is remarkably consistent. Each page follows a standard format, with good use of white space in the margins and helpful running titles. The typography is crisp and unpretentious, and the choice of black lettering on a white background makes for superb reading comfort. Eyestrain was not a problem, even after several hours' perusal. The text is refreshingly free of advertising material.

Hypertext capability is well developed. The index contains many more keywords than I woukt ever need, and they provide direct links to specific pages. Moreover, even without the index, I was able to jump from any point in the text to any other point with just a flick of the

\section{BCR activates new netLibrary Ready Reference Collection}

Participants in the Bibliographic Center for Research (BCR) netLibrary Ready Reference Collection now have access to more than 3,600 wrist. Thanks to a thematic organizational structure, navigation is intuitive.

Graphics are of high resolution, suitable for photocopying, tracing, digital scanning, creating transparencies, or displaying via opaque projectors. Although impressive in their high definition, the illustrations never overpower the text or distract the reader.

It is clear who is responsible for this work's intellectual content because the author is identified on a page bearing the official title. His credentials, however, are not listed. The sponsoring institution is also prominenty named, although no contact information is provided.

The lack of citations and links to other sources does beg the question of how much faith to put in the author's expertise. Granted, his bias towards physics in general, and relativity in particular, is clearly stated from the opening page. Still, prudence is in order. Verification of facts is certainly recommended, particularly in the mathematical formulas.

The version I reviewed is unambiguously identified as the second edition, and the strongest indication that the work is complete, and is not still under construction, is the final paragraph, which begins "Last and not least . .."

Finally, treating usage as a valid criterion, I judge this resource to be very worthwhile. More than one page boasts the telltale dog-ear image registering its usefulness, not to mention occasional smudges, underlines, and annotations indicative of heavily used pulp-based information sites. Einstein's treatise has been accessed 48 times by users outside the library, and presumably even more times by intralibrary users.

Highly recommended as a content-rich, fiber-based reference, despite an avowedly selective scope and relatively narrow focus.

URL: $5301 \mathrm{E} 35 \mathrm{~m}$ or alternate location QC6 .E43 1945. Accessible from any library that owns it or has interlibrary loan capabilities.-Kirk Doran, Dickinson College, doran@dickinson.edu.

electronic books. In addition, more than 400 CliffNotes have been included in the collection and are available with four simultaneoususer access privileges. Ready Reference participants may also order the OCLS WorldCat 
Collection set of bibliographic records at no additional charge. Pricing for academic institutions, including access fees, is based on the number of full-time equivalents (FTEs) employed at the institutions. The Ready Reference Collection is not a subscription service; participating libraries pay a one-time fee

\section{WilsonWeb offers increased access to full-text periodicals}

More than 1,700 periodicals from $\mathrm{H}$. W. Wilson databases are currently featured in full text through the company's WilsonWeb product. Full-text articles are now accompanied by PDF page images, making the charts, graphs, photos, and illustration in articles readily available to researchers. Search options have also been expanded, allowing users to link to full text residing on any of their library's databases that are open-URL compliant. Coverage decisions for many of the Wilson periodicals databases are made with the help of ALA's Reference and User Services Association's (RUSA) Committee on Wilson Indexes, along with subscriber vote

\section{First project underway at OCLC's new preservation center}

A project to microfilm a selection of titles from the University of Minnesota's (UM) collection of monographs chronicling the history of British-Indian interaction is the first reformatting project for the new OCLC Digital \& Preservation Resources (DPR) Western Center in Lacey, Washington. Services offered by the DPR
Western Center include, training and consulting in a variety of areas related to digitization and preservation; $35 \mathrm{~mm}$ high-contrast and continuous tone preservation microfilming; bitonal, grayscale, and color digitization of documents, books, and special collections; and creation of structural, descriptive, and administrative metadata for digitized materials. UM contracted with OCLC Digital \& Preservation Resources for microfilm preparation services and high-contrast microfilming of several volumes from the Ames Library of South Asia.

\section{Digitally recorded textbooks available through RFB\&D}

Recording for the Blind and Dyslexic (RFB\&D), the nation's largest educational library for students who are blind, visually impaired, or have learning disabilities such as dyslexia, has unveiled its AudioPlus digitally recorded textbooks. The inaugural collection includes 6,000 digitally recorded education titles, which complement RFB\&D's existing collection of more than 91,000 accessible textbooks on analog tape. The digital textbooks provide students with instant access, convenience, and better audio quality. To listen to the AudioPlus digitally recorded textbooks, students need a portable CD player equipped to play RFB\&D's books or a standard multimedia computer equipped with a CD-ROM drive and specialized software. RFB\&D offers individual memberships to students as well as insticutional memberships.

\section{Poster session presenters sought for ACRL National Conference}

Share your expertise in a national forum! Present a poster session at the ACRL 11th National Conference in Charlotte, April 1013, 2003.

Poster sessions are informal presentations featuring innovative projects or solutions to problems. These presentations provide a forum for developing contacts among librarians interested in similar issues and are an easy way to get involved at the national level. Poster sessions also provide an opportunity to creatively develop your ideas and get name recognition without the stress of peer review.
Applications are available at www.ala org/acrl/charlotte/program/callform.html The deadline for submission is November 4, 2002.

Completed applications should be sent to: Lynn Scott (Scottie) Cochrane, Director of Libraries, Denison University, Box L, Granville, OH 43023; phone: (740) 587-6215; fax: (740) 587-6285; e-mail: ACRLPOSIERSg denison edu.

More information about ACRL's National Conference, including details about registration can be found at www.ala.org/acrl/charlotte. Questions? Contact (800) 545-2433, ext. 2523; e-mail: acrl@ala org 